\title{
ANATOMICAL CONSIDERATIONS AND CLINICAL IMPLICATIONS OF SUBCLAVIAN ARTERY
}

\author{
Poonam ${ }^{1}$, Naresh Jyoti², Rajan K. Singla ${ }^{3}$, Tripta Sharma ${ }^{4}$
}

\section{HOW TO CITE THIS ARTICLE:}

Poonam, Naresh Jyoti, Rajan K Singla, Tripta Sharma. "Anatomical considerations and clinical implications of subclavian artery". Journal of Evolution of Medical and Dental Sciences 2013; Vol2, Issue 29, July 22; Page: 5484-5491.

\begin{abstract}
AIMS: The knowledge of normal and variant anatomy of subclavian artery in terms of its origin, dimensions, course and relations is mandatory in various diagnostic, interventional and surgical procedures. This study was conducted to aware the surgeon for possible variations in this region and their clinical significance. MATERIAL AND METHODS: 60 subclavian arteries belonging to 30 cadavers were dissected. Various parameters were studied regarding subclavian artery. Site and mode of origin, level of origin, diameter at its origin and termination, length of subclavian arteries, maximum distance coursed by artery above clavicle and its relations. RESULTS: In one specimen, anomalous origin of right subclavian artery was encountered. High arched subclavian were noted in another specimen with deviated course and arching close to pleural apex. Level of origin on left side was constant while right side showed variability. Mean values of morphological measurements were calculated. Relation with vagus and phrenic nerves were found to be normal. CONCLUSION: Knowledge of variant anatomy of subclavian artery must be kept in mind while performing surgeries on head and neck and upper thorax. Less critical knowledge of anatomy of the subclavian artery would lead to troublesome complications.
\end{abstract}

INTRODUCTION: In anatomy, normality embraces a range of morphologies. It includes those that are most common and others called "variations" which are less frequent but not considered abnormal. These variations ranging from subtle to remarkable affect every part of the human body. They may have important influences on predisposition to illness, symptomatology, clinical examination, investigation and patient management including operative surgery. Recognition of variations enables clinicians to distinguish features which merit further investigations or treatment from those which do not ${ }^{1}$.

Subclavian artery is the major artery supplying upper limb, thorax, head and neck and brain. Origin of subclavian artery is different on right and left sides. On right side it arises from brachiocephalic trunk behind the right sternoclavicular joint and on left side from aortic arch in superior mediastinum and passes into root of neck. In the root of neck each artery arches across the dome of pleura behind the scalenus anterior muscle which divides it into three parts viz. first, second and third part $2,3,4$. The extent to which the artery rises above the clavicle varies from 1.2 to $2.5 \mathrm{~cm}^{2}$.

Variations in origin, course and relations of subclavian arteries are not infrequent and many of these have been furnished earlier in literature. Right subclavian artery may arise above or below sternoclavicular level; it may be a separate branch coming directly as the first or last branch of the aortic arch. When first, it is in the position of the brachiocephalic trunk and when last it arises from arch's left end, ascending obliquely to the right behind the trachea, oesophagus and right common carotid to the first rib. Left subclavian is occasionally combined at its origin with left common carotid 4 . Daseler and Anson came across a bilateral malposition of subclavian artery both situated anterior instead of posterior to scalenus anterior muscle 5 . 
MATERIAL AND METHODS: 60 subclavian arteries belonging to 30 cadavers were dissected. Following observations were made regarding subclavian artery.

i. Source of origin of arteries.

ii. Level of origin

iii. Length

iv. External diameter at origin and termination

v. Max distance coursed by artery above clavicle - For measuring the maximum distance coursed by subclavian artery above the clavicle, a scale was kept horizontally in the dissection area touching the uppermost surface of the artery at its highest position above the clavicle. Then the vertical distance between this scale at the point where it touches the artery (highest position of artery above the clavicle) and the upper surface of the clavicle was measured with vernier caliper.

vi. Course and relations of subclavian artery were studied.

RESULTS: ORIGIN: In one, out of 59 limbs, abnormal origin of subclavian artery was encountered, where the right subclavian artery instead of brachiocephalic trunk emanated directly from arch of aorta distal to origin of left subclavian artery and coursed towards right, first horizontally behind the oesophagus and then vertically upwards to reach its normal position. Such a right subclavian artery named as retroesophageal right subclavian artery (RRSA). (Fig 1)

LEVEL OF ORIGIN: While the left subclavian artery in all the 30 limbs of the present study emanated at the usual level of the disc between $\mathrm{T}_{3}$ and $\mathrm{T}_{4}$ vertebrae, the normal level of origin of right subclavian artery i.e. behind the right sternoclavicular joint was seen in 27 (90.0\%) limbs only. In one limb it originated below and in another above and lateral to the sternoclavicular joint. In cadaver, where there was an anomalous retroesophageal right subclavian artery, it took origin from aortic arch at level of disc between $\mathrm{T}_{3}$ and $\mathrm{T}_{4}$. (Fig1)

LENGTH: The average length of right subclavian artery in the present study was found to be 7.8 $\mathrm{cm}$ (Range $6.0-12.9 \mathrm{~cm}$ ) and of left subclavian artery was $9.5 \mathrm{~cm}$ (range $7.5-13.3 \mathrm{~cm}$ ). Anomalous right subclavian artery arising from aorta distal to origin of left subclavian artery was abnormally long as it has to run a long distance. Its total length was $12.3 \mathrm{~cm}$, the length of Ist, $2 \mathrm{nd}$ and $3 \mathrm{rd}$ parts were $7.8 \mathrm{~cm}, 1.3 \mathrm{~cm}$ and $3.2 \mathrm{~cm}$ respectively. Bilaterally curved and high arched subclavians found in one cadaver were also longer having length of 12.9 on right and $13.3 \mathrm{~cm}$ on left.

DIAMETER: The average external diameter of right subclavian artery at its origin was found to be $8.7 \mathrm{~mm}$ (range $6.0-14.5 \mathrm{~mm}$ ) while the same on left side was $9.4 \mathrm{~mm}$ (range $6.0-14.0 \mathrm{~mm}$ ). The corresponding figures at the termination of right and left subclavian artery were $7.3 \mathrm{~mm}$ (range 5-6.4 mm) and 7.2 $\mathrm{mm}$ (range 5-10.1 mm) respectively. Diameter of RRSA was found to be $12 \mathrm{~mm}$ at origin and $8.2 \mathrm{~mm}$ at termination. High arched subclavian arteries were also dilated with diameter of $14.5 \mathrm{~mm}$ and $14 \mathrm{~mm}$ at their origin on right and left sides respectively.

MAXIMUM DISTANCE COURSED BY ARTERY ABOVE CLAVICLE: In the present study it ascended for a distance of $1.8 \mathrm{~cm}$ on an average (Range $1.0-3.2 \mathrm{~cm}$ ) on the right side and of 1.9 $\mathrm{cm}$ (range $0.8-2.9 \mathrm{~cm}$ ) on the left. In one specimen, subclavian artery rose to the level of 3.2 and $2.9 \mathrm{~cm}$ above the clavicle on right and left sides respectively. (Fig $2 \& 3$ ). 


\section{VARIATIONS IN COURSE AND RELATIONS OF SUBCLAVIAN ARTERY:}

In three specimens course of subclavian artery was deviated from normal. In one there was retro-esophageal right subclavian artery with abnormal length and diameter as discussed above. High arched subclavian arteries were encountered bilaterally in one cadaver with their highest point lying at the same level as of pleural apex. These arteries were abnormally curved and dilated. (Fig 2,3). Remaining cadavers were showing the subclavian arch crossing the dome of pleura below the level of pleural apex. Relation with phrenic and vagus nerve were normal in all. (Fig $4 \& 5$ ).

DISCUSSION: According to standard textbooks of anatomy, the right subclavian artery originates from the brachiocephalic trunk and the left from the arch of aorta. This was true in 59 limbs (98.33\%) of the present study except in one (3.33\%), where RRSA was found. Such an artery has been encountered in the past by various workers in the prevalence range of $0.4-2 \%$ (5-11).

Gross thoroughly reviewed the surgical importance and therapy of anomalous right subclavian artery arising as last branch of aortic arch and crossing behind the oesophagus. He analysed that in some of these cases, it leads to pressure on the oesophagus leading to dysphagia lusoria, and then complete relief is obtained by simple ligation and division of anomalous subclavian artery ${ }^{12}$.

Such a condition appears due to defect in absorption of primitive right aortic arch in the embryo. Under normal circumstances, the absorption occurs distal to the point of origin of right subclavian artery. But in such cases, the absorption occurs along the fourth arterial arch and the embryonic right aorta becomes the right subclavian artery. Cobey speculated that such anomalous artery might produce symptoms resembling cervical rib and trophic changes in the arm, forearm and hand6.

Kommerell's diverticulum is commonly (60\%) associated with ARSA ${ }^{13}$. Kommerell's diverticulum is defined as a dilatation of the proximal portion of an aberrant subclavian artery near its origin from the aorta ${ }^{14}$. It represents the remnant of the distal right aortic arch in the left aortic arch with ARSA, and the remnant of the left dorsal aortic root in the right aortic arch with ALSA. In our study, Diameter in RRSA was much more than average. This condition might be due to Kommerell's diverticulum.

Average length of left and right subclavian arteries found in our study is comparable to Romanes $^{2}$ whose corresponding figures are 7.5 and $10 \mathrm{~cm}$ on right and left sides respectively. The length of the subclavian artery is more on the left side as compared to right side. It may be attributed to the fact that on the left side, it arises from the arch of aorta situated at a lower level while on right side, it arises from brachiocephalic trunk situated at a higher level, and thus the left subclavian artery has to run a longer distance than its counterpart to reach its destination.

The inner diameter of the blood vessels should be considered in endovascular surgery while insertion of guiding catheter within a major branch. The inner diameter of major branches of aortic arch varies depending on investigators ${ }^{15}$. In our study, average external diameter at origin was found to be $8.7 \mathrm{~cm}$ on right and $9.4 \mathrm{~cm}$ on left side. Such data could be helpful in selection of appropriate size of guiding catheter.

According to Anson ${ }^{3}$ the subclavian artery ascends to $2 \mathrm{~cm}$ above the clavicle. In persons with slender neck and sloping shoulders, the arch is likely to be high while in short necked persons it may not appear above the clavicle ${ }^{16}$. The close proximity of the subclavian artery to pleural cupola and pulmonary apex renders this vessel extremely liable to injury in procedures such as open and especially closed pneumolysis. These vessels are also liable to injury in 
performance of thoracoplasty and other surgical procedures requiring resection of $1 \mathrm{st}$ rib, so in these instances less critical knowledge of anatomy of the subclavian artery and its branches would lead to hazard in surgery of neck and upper thorax ${ }^{5}$.

The subclavian artery, in the medial portion of its course, though well protected by overlying sternocleidomastoid muscles, and inner end of clavicle is yet liable to injury by penetrating wounds in the lower neck region. While ligating the artery in first and second part of its course, one must bear its relationship with pleura in mind ${ }^{16}$.

Abnormally curved and dilated arteries were encountered in one cadaver of our study. Kim \& Suh reported that in cases with curved blood vessel; and poor angulation with arch of aorta, difficult in advancement due to selection of a guide catheter were reported. This is because a selection vessel could contribute to an embolism from atheroma of aortic $\operatorname{arch}^{17}$. The major branches of arch of aorta are the great ways for blood supply to head and upper limb and are of particular interest in clinical angiography. The proximal segments of these branches are common sites for atherosclerosis with critical consequences for blood supply to brain ${ }^{18}$.

Another important clinical entity described to be related with subclavian artery is the "subclavian steal syndrome". It is because of occlusion or stenosis of the proximal portion of the artery leading to a decreased blood pressure in its distal part resulting in a blood flow from the opposite vertebral artery to basilar artery and then a retrograde flow through ipsilateral vertebral artery to supply distal part of subclavian artery. This siphoning of blood from vertebrobasilar system to subclavian leads to transient cerebral ischaemia or even a major stroke and named as subclavian steal syndrome ${ }^{19}$.

Blalock \& Taussig could not find significant interference in blood supply of the corresponding upper limb in which subclavian artery was sacrificed for management of pulmonary stenosis. They attributed it to the rich and abundant collaterals via axillary artery. Simultaneously, they cautioned against the heavy physical labour or athletic endeavours of the limb as these collaterals may not meet increased demand during such situations ${ }^{20,21}$.

CONCLUSION - Less critical knowledge of anatomy of the subclavian artery and its branches would lead to hazard in surgery of neck and upper thorax. Morphometric measurements taken in this study can assist surgeons in performing safe and effective surgeries. In the light of so many clinical entities caused by variable anatomy of this vessel (vide supra) it becomes imperative for thoracic surgeons and those interpreting radiographs and CT scans of the region to have its different variational patterns at their finger's ends.

\section{BIBLIOGRAPHY}

1. Willan PLT and Humpherson JR. Concepts of variation and normality in morphology: Important issues at risk of neglect in modern undergraduate medical courses. Clin Anat 1999; 12: 186-190.

2. Romanes GJ. The blood vascular and lymphatics system. In: Cunningham's Text Book of Anatomy. 10th ed. Oxford University Press London, New York, Toronto 1964; 882-885.

3. Anson BJ. The cardiovascular system-Arteries and veins, Thomas M Oelrich edr. In: Morris Human Anatomy. 12 $2^{\text {th }}$ Edn. The Blakiston Division McGraw Hill Book company, 1966; 613-858.

4. Williams PL, Bannister LH, Berry MM, Collins P, Dyson M, Dussek JE et al. Cardiovascular system - subclavian system of arteries, Gabella G Edr. In: Gray's Anatomy. 38 $8^{\text {th }}$ Edn, Churchill Livingstone, New York, London, 1995; 1529-1536. 
5. Daseler and Anson BJ. Surgical anatomy of subclavian artery and its branches. Surg Gynaecol Obstet. 1959; 108: 149-174.

6. Cobey JF. An anomalous right subclavian artery. Anat Rec. 1914; 8: 15-19.

7. Weinberger G, Randall PA, Parker FB, Kieffer SA. Involvement of an aberrant right subclavian artery in dissection of the thoracic aorta: diagnostic and therapeutic implications. Am J Roentg. 1977; 129: 653-655.

8. Gross RE and Ware PF. The surgical significance of aortic arch anomalies. Surg Gynaecol Obstet. 1946; 25: 687-700.

9. Nathan $\mathrm{H}$ and Seidel MR. The association of a retroesophageal right subclavian artery, a right sided terminating thoracic duct and a left vertebral artery of aortic origin. Anatomical and Clinical considerations. Acta Anat. 1983; 117: 362-373.

10. Pattinson JN. Anomalous right subclavian artery. Br Heart J 1953; 15: 150-158. Cited by Nathan $\mathrm{H}$ and Seidel MR. The association of a retroesophageal right subclavian artery, a right sided terminating thoracic duct and a left vertebral artery of aortic origin. Anatomical and Clinical considerations. Acta Anat. 1983; 117: 362-373.

11. Calleja F, Eguaras M, Montero J, Granados J, Garcia Jimenez MA,Suraez de Lezo J et al. Aberrant right subclavian artery associated with common carotid trunk. Eur J of Cardiothorac Surg. 1990; 4: 568-570.

12. Gross RE. Surgical treatment of dysphagia lusoria. Ann Surg. 1946; 124: 532-534.

13. Donnelly, LF, Fleck, RJ, Pacharn, P, Ziegler, MA, Fricke, BL, Cotton, RT. Aberrant subclavian arteries. Am J Roentgenol 2002; 178: 1269-1274.

14. Freed, K, Low, VH. The aberrant subclavian artery. Am J Roentgenol 1997; 168: 481484.

15. Gupta M, Sodhi L. Variations in branching pattern, shape, size and relative distances of arteries arising from arch of aorta. Nepal Med Coll J. 7:13-17; 2005.

16. Anson BJ and Maddock WG. The neck In: Callander's Surgical Anatomy, 3rd Edn. WB Saunders Company, Philadelphia, London 1952: 224-235 \& 251.

17. Kim HJ, Suh DC. Atherosclerotic carotid stenosis. Recent update of carotid stenting.Neurointervention.1: 7-17; 2006.

18. Zamir M and Sinclair P. Origin of brachiocephalic trunk, left carotid and left subclavian arteries from the arch of human aorta. Invest Radiol 1991; 26: 128-133.

19. Singh S and Singh SP. Atresia of vertebral artery and its clinical significance. Neurol Ind 1971; 4: 172-176.

20. Blalock A and Taussig H. Surgical treatment of malformations of the heart in which there is pulmonary stenosis or pulmonary atresia. J Am Med Ass 1945; 128: 189-202.

21. Blalock A. A study of the surgical treatment of congenital pulmonic stenosis. Ann Surg 1946; 124: 879-887. 


\section{ORIGINAL ARTICLE}

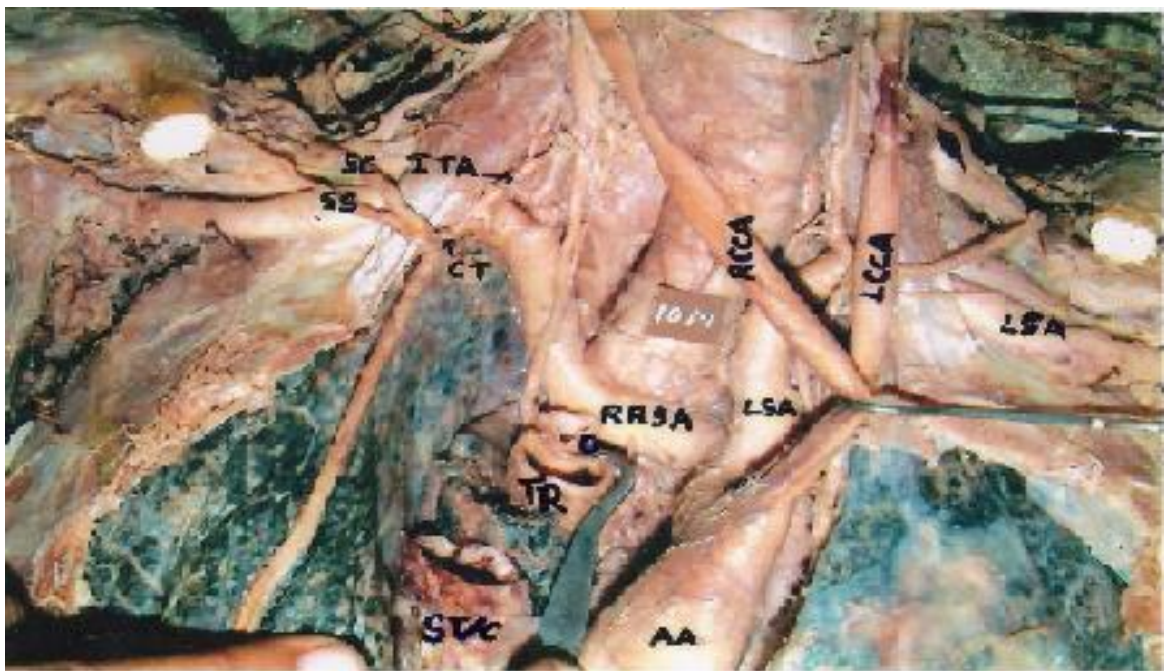

Fig 1. Retroesophageal Right subclavian artery (RRSA) coming from arch of aorta distal to left subclavian artery (LSA). [LCCA and RCCA: Left and Right common carotid arteries; Tr \& 0: cut lower ends of trachea and oesophagus]

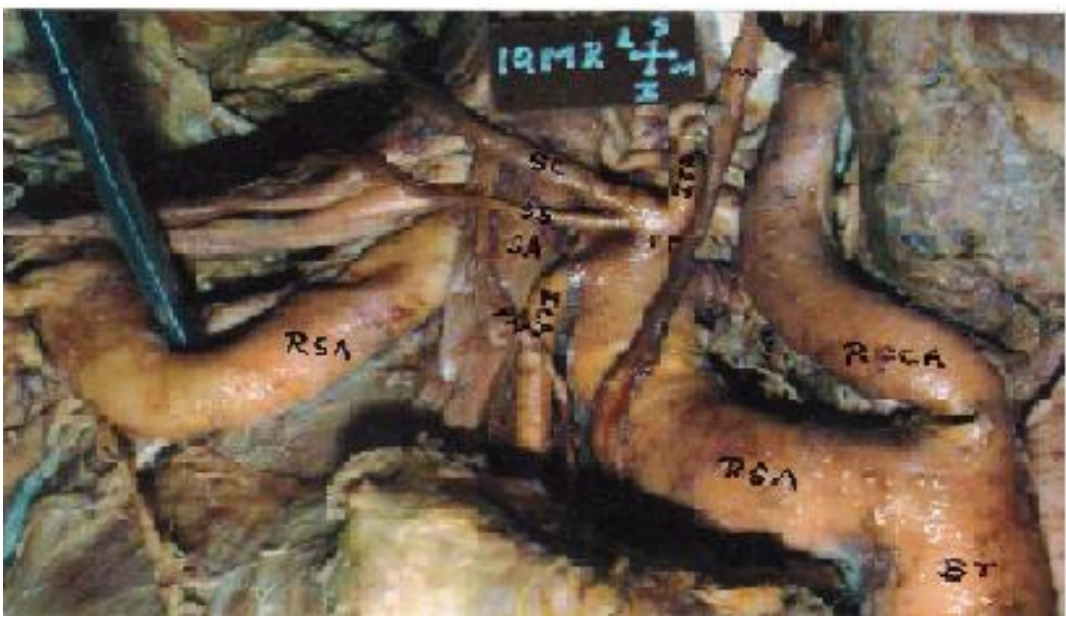

Fig 2. Abnormal S-shaped curve of High arched right subclavian artery (RSA).

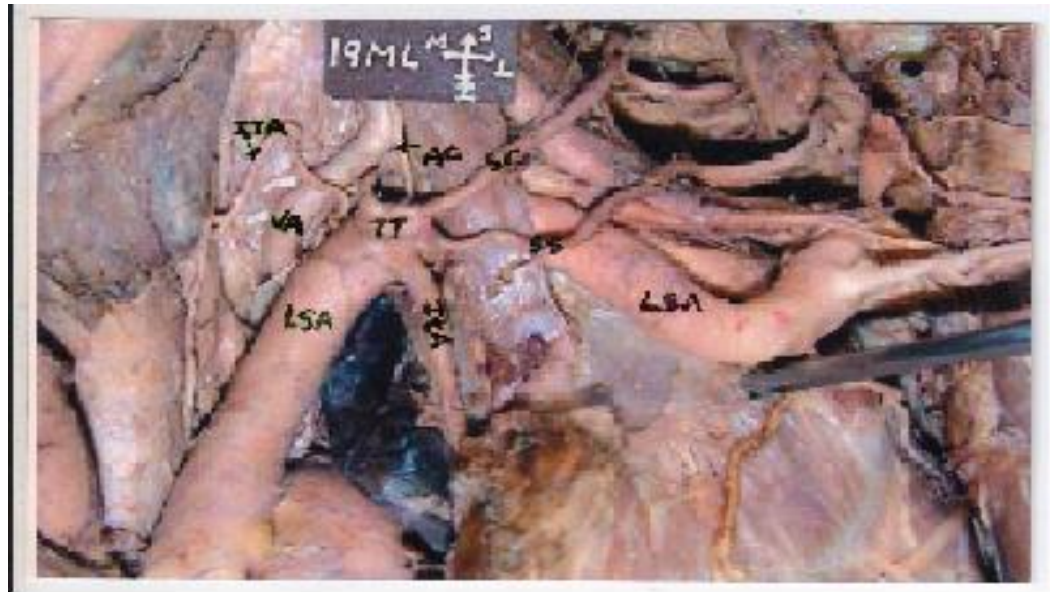

Fig 3. Abnormal course of High arched left subclavian artery (LSA) and Subclavian arch lying close to pleural apex. 


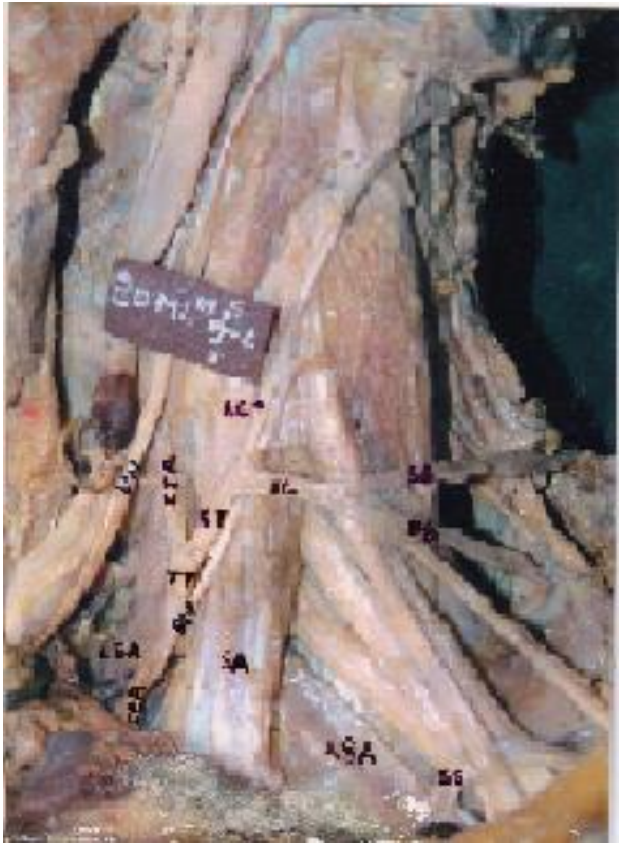

Fig 4. Showing normal course and relations of left subclavian artery (LSA).

[PN: Phrenic nerve; SA-Scalenus anterior; TT- Thyrocervical trunk; ITA-Inferior thyroid artery]

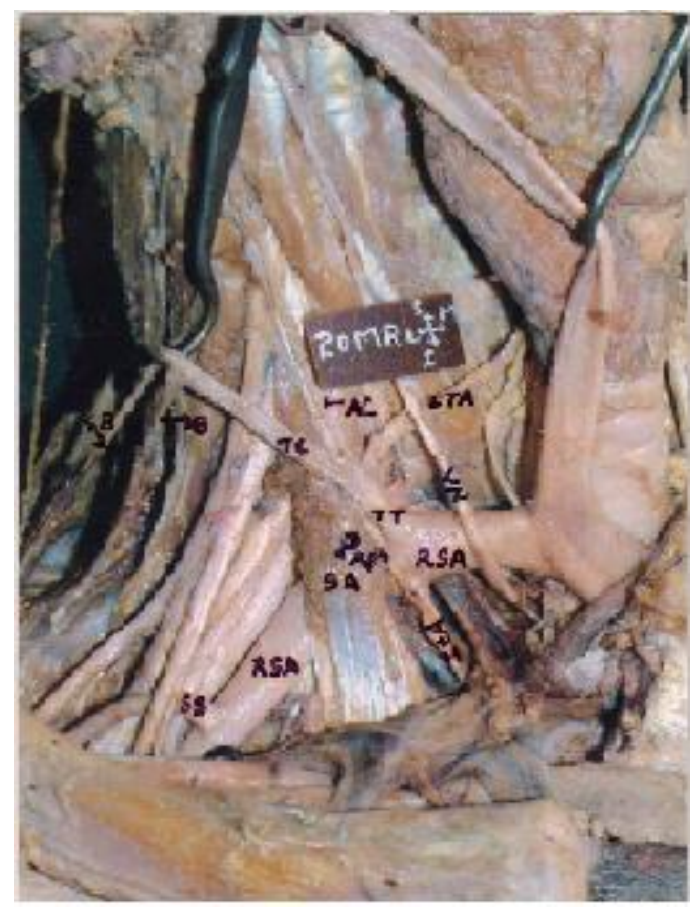

Fig 5. Showing normal course and relations of right subclavian artery (RSA). [PN: Phrenic nerve; VN-Vagus nerve; SA-Scalenus anterior; TT- Thyrocervical trunk; ITA-Inferior thyroid artery] 


\section{AUTHORS:}

1. Poonam

2. Naresh Jyoti

3. Rajan K Singla

4. Tripta Sharma

\section{PARTICULARS OF CONTRIBUTORS:}

1. Associate Professor, Department of Anatomy, Chintpurni Medical College, Bungal, Pathankot, Punjab.

2. Associate Professor, Department of Anatomy, Chintpurni Medical College, Bungal, Pathankot, Punjab.

3. Additional Professor, Department of Anatomy, Govt. Medical College, Amritsar, Punjab.
4. Professor \& HOD, Department of Anatomy, Punjab institute of Medical Sciences, Jallandhar, Punjab

\section{NAME ADRRESS EMAIL ID OF THE CORRESPONDING AUTHOR:}

Dr. Poonam, 91 - Ram Sharnam Colony, Pathankot, Punjab.

Email-drpoonamdel@yahoo.co.in

Date of Submission: 23/06/2013.

Date of Peer Review: 24/06/2013.

Date of Acceptance: 16/07/2013.

Date of Publishing: 22/07/2013 